\title{
A transição da estrutura organizacional simples para uma burocracia profissional - o caso da Sempre Bela Cabeleireiros
}

\section{The transition of simple organizational structure to professional bureaucracy - the case of Sempre Bela Cabeleireiros}

\author{
Carlos Roberto Domingues ${ }^{1}$ \\ Janaina Maria Bueno ${ }^{2}$ \\ Pedro Paulo Melo Arantes ${ }^{3}$ \\ Guilherme Afrânio Machado ${ }^{4}$ \\ Guilherme Nascimento Medeiros ${ }^{5}$
}

\begin{abstract}
Resumo
Caso para ensino baseado na história de um salão de beleza que passou, ao longo de duas décadas, por mudanças na sua estrutura organizacional. O objetivo foi demonstrar e analisar duas diferentes configurações da estrutura organizacional, com suas características e desafios de gestão, tendo como referência o modelo de configurações de Mintzberg (2015). A históriado Sempre Bela Cabeleireiros aborda a criação e expansão de um salão de beleza em uma cidade de porte médio. Os fatos demonstraram que estruturas simples enfrentam dificuldades na transição para a burocracia profissional, principalmente na mudança de postura com relação à descentralização do poder. $\mathrm{O}$ caso para ensino pode ser utilizado por estudantes de graduação em administração em disciplinas que versem sobre empreendedorismo e gestão organizacional.

Palavras-chave: Empreendedorismo. Estrutura Organizacional. Burocracia Profissional. Transformação Organizacional.

Abstract

This teaching case was based on the story of a beauty salon that changed its organizational structure for two decades. It aims to demonstrate and analyze different configurations of organizational structure, with its characteristics and management challenges using as reference the model of configuration structures by Mintzberg (2015). The story of Sempre Bela Cabeleireiros discusses the creation and expansion of a beauty salon in a mid-sized city. The facts have shown that simple structure face difficulties in the transition to the professional bureaucracy, especially in the change of posture with decentralization of power. The teaching case might be used by undergraduate students in business administration in disciplines o fintrapreneurship and organizational management.
\end{abstract}

Keywords: Intrapreneurship. Organizational. Structure. Professional Bureaucracy. Organizational Transformation.

\section{Introdução: Um começo modesto}

De uma família com poucos recursos, Mariquinha decidiu parar de estudar para começar a trabalhar como manicure em um pequeno salão. Lá, ela aprendeu as atividades da profissão e desenvolveu novas habilidades até chegar a ser cabeleireira.Atualmente, Mariquinha é uma empresária bem-sucedida, conta com seis unidades de salões de beleza espalhados pela cidade, trabalha e administra o seu empreendimento

Doutor em Administração pela Fundação Getúlio Vargas - São Paulo. Brasil. Afiliação: Professor Adjunto da Faculdade de Gestão e Negócios - Universidade Federal de Uberlândia. Lattes: http://lattes.cnpq.br/4672727057809200 Email: carlosdomingues@yahoo.com

2 Doutora em Administração pela Fundação Getúlio Vargas - São Paulo. Brasil. Afiliação: Professora Adjunta da Faculdade de Gestão e Negócios - Universidade Federal de Uberlândia. Lattes: http://lattes.cnpq.br/9091229487265299 Email: janainabueno@fagen.ufu.br

3 Graduado em Administração. Faculdade de Gestão e Negócios/Universidade Federal de Uberlândia - FAGEN/UFU. Brasil. Afiliação: Universidade Federal de Uberlândia-UFU. Lattes: http://lattes.cnpq.br/7887295327021771Email: pedropauloadm@yahoo.com.br

4 Graduado em Administração. Faculdade de Gestão e Negócios/Universidade Federal de Uberlândia - FAGEN/UFU. Brasil. Afiliação: Universidade Federal de Uberlândia-UFU. Lattes: http://lattes.cnpq.br/8761381250274817 Email: guii_machado@hotmail.com

5 Graduado em Administração. Faculdade de Gestão e Negócios/Universidade Federal de Uberlândia - FAGEN/UFU. Brasil. Afiliação: Universidade Federal de Uberlândia-UFU. Email: gui_1405@hotmail.com 
há mais de duas décadas, o qual é muito conhecido pelos moradores da cidade e regiões vizinhas, com o nome de "Sempre Bela Cabeleireiros", apoiado por uma estrutura organizacional que efetivamente passou por transformações.

Desde o início como manicure até o momento atual, como reconhecida empresária do setor da beleza, Mariquinha enfrentou muitos desafios e,para superá-los,contou com a ajuda de diferentes pessoas. Em meados da década de 1990, com o auxílio financeiro de sua família, montou seu primeiro salão, que era bastante simples,e onde ela mesma executava todas as funções: recepção aos clientes serviços de manicure e pedicure, cortes de cabelo, venda de produtos, cobrança dos serviços e limpeza do salão.

Devido à qualidade do seu serviço,aliado à sua simpatia, o salão foi sendo cada vez mais procurado, mas Mariquinha entendeu que o seu empreendimento ainda não apresentava tantas atividades complexas a ponto de demandar a contratação de um auxiliar e aumentar a complexidade de sua estrutura. Esta realidade continuou até o momento em que ela começou a observar os clientes ajudando na rotina do salão, seja fazendo o próprio troco ou auxiliando nos serviços. Ao perceber essa situação, ela teve que encarar seu receio e desconfiança em ter alguém para ajudá-la e contratar uma profissional para realizar as atividades de limpeza e assistência nos serviços básicos do salão.Apesar da ajuda recebida, seu estilo de trabalho não tolerava falhas de outras pessoas. Assim, seu excesso de controle em tratar as rotinas, bem como seu grau de perfeccionismo, aumentou a dificuldade em se relacionar com a nova profissional e prejudicou o desenvolvimento dela, pois Mariquinha julgava que, como proprietária do empreendimento, era ela quem deveria assumir todas as suas atividades e responsabilidades. Entretanto, algo lhe dizia que sua estrutura organizacional não estava adequada e que não seria dessa forma que superaria suas inquietações.

Com o passar do tempo e o sucesso do negócio, a demanda sobre si fez com que Mariquinha precisasse aumentar sua capacidade, atendendo mais clientes por dia. Por consequência, ampliou seu espaço físico para suportar a contratação de novos auxiliares e oferecer outros serviços. Concomitantemente, sentindo a necessidade de aprimorar-se em novas técnicas e procedimentos de gestão e controle, recorreu aos empréstimos bancários e à família, e passou a fazer uso de anotações em um livro caixa obtido com um amigo que era contador.

Em um primeiro momento, o resultado foi muito satisfatório, com aumento do fluxo financeiro e a necessidade de contratação de profissionais mais habilitados, com conhecimento e experiência para atuar no mesmo nível que ela. Entretanto, sua maior dificuldade não era encontrar profissionais com competência técnica, mas sim para encontrar alguém em quem confiasse. A capacidade de confiar em um novo empregado foi um critério sempre presente nas suas escolhas para contratação, mas sentia que as soluções para suas preocupações iam além dos elementos relativos às pessoas, estavam voltadas para o formato do negócio e a estrutura da empresa.

Mesmo diante desse crescimento e com sinais de que o empreendimento se manteria, a expansão continuou sendo considerada um risco para Mariquinha, que postergou o máximo possível a criação de novas unidades. No entanto, com o aumento constante do número de clientes, resultado do reconhecimento do mercado quanto à qualidade dos serviços, refletido na proximidade e personalização do atendimento, o crescimento tornou-se inevitável.

Ofertas constantes de novos produtos e serviços,além da popularidade do salão atestada por matérias sobre na televisão e em revistas locais, contribuíram igualmente para o aumento da demanda. Fazia-se presente, contudo, o fantasma de contratar pessoas com as características "ideais", além do ponto comercial e a decoração adequada. Além disso, não lhe saía da cabeça a necessidade de melhor compreender sua empresa: como estava estruturada e como deveria ser no futuro, quando crescesse, pois a empresa não poderia depender somente dela para seguir em frente.

\subsection{A empreendedora}

Apesar da resistência e desconfiança de Mariquinha,a sua aptidão para os negócios falou mais alto e, desse modo, cinco anos após a inauguração do primeiro salão de beleza, nasceu sua segunda unidade que, a pedido de algumas clientes, foi instalado estrategicamente em um bairro nobre da cidade. 
Surgiram, então, novos desafios de gestão, o que demandou uma abordagem diferente no que diz respeito ao controle e organização do negócio, para que fosse possível gerenciar sua estrutura. Mariquinha sentia o desejo de colocar no papel como era a sua estrutura para melhor coordenar as pessoas e os dados financeiros, mantendo principalmente, a qualidade dos serviços, pois Ihe incomodava saber que a empresa estava muito dependente dela. Emergiu daí a necessidade de um gestor de confiança e, para tanto, ela buscou em seu quadro de funcionários a pessoa mais antiga e ofereceu-lhe o cargo de gerente da segunda unidade. Juntas, elas tentaram organizar melhor a compra e estoque de produtos, as horas trabalhadas pelos profissionais e o controle de entrada e saída de caixa, mas esses controles ainda eram manuais e não havia nenhum sistema informatizado, nem mesmo para cadastro de clientes.

Anova estrutura, com novas atividades e novos controles,aumentou a pressão sobre a agenda da fundadora que, além de continuar com as atividades de cabeleireira, também controlava as atividades administrativas e financeiras junto com sua gerente, mas utilizando o tal livro caixa e outras "folhinhas de anotações".Apesar de todo o trabalho extra para Mariquinha, no entanto, a aposta em uma nova unidade se mostrou extremamente acertada.

Os resultados surpreenderam-na de forma positiva e impulsionaram a abertura de uma terceira unidade. Mariquinha repetiu o processo da unidade anterior sobre a escolha dos profissionais, ambiente e estrutura física, ou seja, além dos critérios técnicos, a confiança continuava sendo um dos principais requisitos. Assim, na terceira unidade também foi escolhida uma profissional com mais tempo de casa para, além de suas atividades como cabeleireira, exercer a função de gerente do salão.

Com três unidades em funcionamento e duas gerentes ajudando na atividade e no controle, Mariquinha notou que suas atividades se intensificaramà medida que passou a ter que dividir seu tempo com idas às unidades para supervisionar e conversar com seus gerentes, além de gerenciar o salão mais antigo e executar suas atividades como profissional do salão.

Com o tempo, Mariquinha passou a perceber que as relações entre os gerentes e suas unidades tornaram-se mais autônomas, o que foi interpretado por ela como se eles se sentissem "donos do negócio". Esse fato aflorou na proprietária um sentimento de desconforto, pois,segundo ela, o negócio estava perdendo sua característica inicial, seu jeito de fazer as coisas, a sua identidade e marca pessoal.Além disso, ela se perguntava se o tal livro caixa e suas "folhinhas" iriam controlar o suficiente e de forma correta.

Nesse momento, surgiu a tendência para ofertar serviços de salão de beleza nos shopping centers. Por Mariquinha ter um perfil empreendedor, a novidade chamou-lhe a atenção a ponto de se aventurar em uma quarta unidade, com novas características, porém,o que implicava em um perfil diferenciado de profissionais, em um grau maior de sofisticação do ambiente e em um leque amplo de produtos e serviços.

\subsection{Um novo pensamento}

Devido às características particulares da nova unidade, instalada no principal shopping da cidade e à necessidade de controlar o negócio, Mariquinha decidiu contratar um profissional para fazer a gestão da unidade. Pela primeira vez, ela contratou alguém de fora do salão, com experiência em administração e loja em shopping center, mas sem conhecimento das atividades e do funcionamento de um salão de beleza. Com o passar do tempo, os resultados mostraram que a aposta de uma unidade no shopping foi extremamente positiva, exceto na gestão.

O fato do gestor não possuir o conhecimento técnico afastou-o da equipe de profissionais, que não o reconheciam como líder ou autoridade. Na opinião dos funcionários, o gerente controlava a unidade com foco nos indicadores financeiros, mas não passava do livro caixa e de algumas fichas de controle de materiais, e também não levava em conta os aspectos inerentes à qualidade dos serviços e à forma de atendimento dos clientes.Assim, o objetivo de Mariquinha, que era obter eficiência e eficácia na nova unidade, porém sem perder o controle e sua identidade, foi alcançado parcialmente. Então, ela substituiu o gerente por um funcionário antigo do salão, pois achou que era mais fácil ensinar a sua forma de gestão para quem entendia do funcionamento do salão. 
Um problema que foi ficando evidente para os funcionários, principalmente aqueles na função de gerente, foi que, mesmo com o crescimento de seus negócios, Mariquinha não dava muita chance para que se destacassem mais do que ela, o que gerou muitas conversas e saídas de profissionais do salão. Mariquinha sentiu-se pressionada, por um lado, a mudar o seu jeito, mas, por outro, não queria perder a essência e identidade da sua empresa.

Percebendo o seu alto grau de envolvimento com a rotina de cada salão, após algumas reuniões com seus gerentes, Mariquinha resolveu criar uma agenda rotativa semanal de permanência em cada uma das unidades, com a adoção de treinamento mensal de seus funcionários no "estilo Mariquinha de fazer". Assim, ela poderia garantir que o estilo e padrão de qualidade fossem mantidos nos serviços. Além disso, eles definiram alguns indicadores de qualidade e financeiros que os gerentes deveriam cuidar e prestar contas à proprietária todo final de mês. Além disso, ela iria pesquisar um sistema informatizado para ajudála e aos gerentes no controle.

No que diz respeito à expansão e criação de novas unidades, ela decidiu manter o critério de seleção de profissionais dentro de seus padrões de confiança, respeito e lealdade, ou seja, aqueles que apresentassem a deferência necessária à Mariquinha e aos seus métodos de trabalho.

Apesar das boas intenções, nem tudo funcionou como o esperado. Mariquinha realizou diversas demissões, que afetaram o ambiente organizacional, principalmente sobre aqueles que não se encaixavam dentro de seus padrões. Por limitações de tempo, ela só conseguiu realizar os treinamentos por curtos períodos, pois sempre achou sua presença era fundamental e suficiente para a formação dos profissionais. Essa situação gerou uma grande dependência de toda a estrutura para com ela e também não sobrou tempo para acompanhar e analisar as informações sobre a gestão e aperfeiçoar os indicadores. O sistema de gestão informatizado nunca foi implantado.

Como tentativa de resolver parte dos problemas, ela tomou a decisão de convidar somente membros próximos da família para gerenciar as unidades, o que tornou a estrutura mais dependente das suas decisões. O quadro 1, a seguir, mostra a sequência de ações realizadas por Mariquinha ao longo dos anos:

Quadro 1 - Principais ações ao longo dos anos

\begin{tabular}{|l|l|}
\hline \multicolumn{2}{|l|}{ Ano x Principais ações do "Sempre Bela Cabeleireiros" } \\
\hline 1997 & Inauguração da primeira unidade. \\
\hline 2000 & Contratação de uma assistente para as atividades de limpeza. \\
\hline 2003 & Ampliação do espaço físico / Contratação de novos auxiliares \\
\hline 2005 & Contratação de cabeleireiros profissionais. \\
\hline 2006 & Inauguração da segunda unidade / Promoção de uma das funcionárias a gerente. \\
\hline 2008 & Inauguração da terceira unidade / Promoção de um funcionário a gerente. \\
\hline 2010 & $\begin{array}{l}\text { Inauguração da quarta unidade (no shopping) / Contratação de um gestor administrativo, } \\
\text { profissional sem conhecimento do funcionamento de um salão de beleza. }\end{array}$ \\
\hline 2014 & Reestruturação / Familiares próximos em cargos de gerência. \\
\hline
\end{tabular}

Fonte: Elaborado pelos autores com base nos dados da empresa estudada.

No quadro 2,é possível observar a evolução do número de cargos e de empregados no mesmo período e a devida forma para efetuar a contratação: 
Quadro 2 - Evolução de cargos e contratações

\begin{tabular}{|c|c|c|c|}
\hline ANO & CARGO & QTDE & $\begin{array}{l}\text { CRITÉRIO DE SELEÇÃO/ } \\
\text { MANUTENÇÃO }\end{array}$ \\
\hline \multirow[t]{2}{*}{1997} & - & 0 & \\
\hline & Total: & 0 & \\
\hline \multirow[t]{2}{*}{2000} & Auxiliar Geral & 1 & Amizade/confiança \\
\hline & Total: & 1 & \\
\hline \multirow[t]{4}{*}{2003} & Cabeleireiros & 4 & Amizade/confiança \\
\hline & Manicure / Pedicure & 5 & Amizade/confiança \\
\hline & Auxiliar geral & 11 & Amizade/confiança \\
\hline & Total: & 20 & \\
\hline \multirow[t]{6}{*}{2005} & Cabeleireiros & 9 & Amizade/confiança \\
\hline & Maquiadores & 4 & Amizade/confiança \\
\hline & Manicure / Pedicure & 11 & Amizade/confiança \\
\hline & Auxiliar geral & 25 & Amizade/confiança \\
\hline & Gerentes & 2 & Amizade/confiança \\
\hline & Total: & 51 & \\
\hline \multirow[t]{6}{*}{2008} & Cabeleireiros & 17 & Indicação/confiança \\
\hline & Maquiadores & 8 & Indicação/confiança \\
\hline & Manicure / Pedicure & 18 & Indicação/confiança \\
\hline & Auxiliar geral & 56 & Indicação/confiança \\
\hline & Gerentes & 3 & Indicação/confiança \\
\hline & Total: & 102 & \\
\hline \multirow[t]{7}{*}{2010} & Cabeleireiros: 27 & 27 & Indicação/confiança \\
\hline & Maquiadores: 15 & 15 & Indicação/confiança \\
\hline & Manicure / Pedicure: 30 & 30 & Indicação/confiança \\
\hline & Auxiliar geral: 105 & 105 & Indicação/confiança \\
\hline & Massagista: 4 & 4 & Indicação/confiança \\
\hline & Gerentes & 4 & Confiança/seleção no mercado \\
\hline & Total & 185 & \\
\hline \multirow[t]{7}{*}{2014} & Cabeleireiros & 26 & Indicação/confiança \\
\hline & Maquiadores & 15 & Indicação/confiança \\
\hline & Manicure / Pedicure & 32 & Indicação/confiança \\
\hline & Auxiliar geral & 115 & Indicação/confiança \\
\hline & Massagista: 5 & 5 & Indicação/confiança \\
\hline & Gerentes & 4 & Familiares \\
\hline & Total: & 197 & \\
\hline
\end{tabular}

Fonte: Elaborado pelos autores com base nos dados da empresa estudada.

Atualmente, o mercado continua em expansão e com necessidade de profissionais atualizados e gestão profissional. O segmento de estética e beleza vem crescendo tanto tecnologicamente (com novos produtos e serviços) quanto com o surgimento de grandes redes de salões. Essa realidade não se restringe às grandes capitais e já está migrando para cidades de porte médio, como a de Mariquinha.Será que o salão de beleza "Sempre Bela Cabeleireiros" conseguirá acompanhar as atuais e futuras mudanças? 


\section{Notas de Ensino}

\subsection{Objetivos Educacionais}

Do ponto de vista do domínio cognitivo, o caso apresentado para ensino tem o objetivo de propiciar o debate e o entendimento dos alunos sobre o conceito de estrutura organizacional por meio da abordagem de configurações organizacionais de Mintzberg (2015). Para auxiliar na consecução do objetivo, foram elencados os objetivos específicos:

1) Identificar as características pertinentes às configurações de estruturas organizacionais.

2) Relacionar duas das configurações explicadas por Mintzberg (2015), a estrutura simples e a burocracia profissional, com a prática evidenciada em organizações que trabalham essencialmente com serviços.

3) Avaliar os efeitos das configurações organizacionais adotadas para a gestão de organizações e consecução de seus objetivos.

4) Avaliar os mecanismos de coordenação empregados.

5) Identificar os controles necessários para a operação, seus processos e indicadores.

O presente caso para ensino mostra-se relevante ao aproximar os alunos do conceito de configuração organizacional, abordagem apresentada por um dos mais importantes autores de estudos organizacionais e estratégia, Henry Mintzberg, de maneira prática e simples, permitindo que os alunos compreendam como o crescimento organizacional implica em mudanças na coordenação, no controle, na delegação, nas rotinas e processos.

\subsection{Fontes de dados}

O caso para ensino foi desenvolvido com base em uma abordagem qualitativa, com pesquisa do tipo descritiva. A abordagem qualitativa tem como pressuposto a percepção de que há uma relação dinâmica entre o mundo objetivo e a subjetividade de quem observa, privilegiando as percepções e a subjetividade (FARIAS FILHO; ARRUDA FILHO, 2013). Como procedimentos técnicos, foram utilizadas a pesquisa bibliográfica e a pesquisa de campo. A pesquisa bibliográfica permitiu a aproximação com o tema e análise de situações práticas apresentadas em outras pesquisas, já a pesquisa de campo trouxe as informações de uma situação específica, onde houve a transição da estrutura organizacional, evidenciando as características específicas de cada momento, bem como seus problemas e desafios.

A coleta de dados da pesquisa de campo foi feita por meio de entrevistas e observação não participante em um salão de beleza composto por cinco unidades. Devido ao fato deste salão (Salão A) já possuir uma estrutura do tipo burocracia profissional na época da pesquisa, resolveu-se coletar mais dados sobre um salão de beleza funcionando com uma estrutura simples, por isso foi feita uma pesquisa adicional em outro salão (Salão B), localizado na mesma cidade.

O objetivo da pesquisa com o último salão foi tão somente de compreender e poder detalhar melhor as características da estrutura simples.Todos os dados da história do Sempre Bela Cabeleireiros, no entanto, foram obtidos com o no próprio salão. A seguir, são mostradas as características de cada salão:

- Salão A: Com mais de duas décadas no mercado, o salão Aé uma empresa de médio porte, situada em uma cidade do interior de Minas Gerais,que conta com aproximadamente duzentos empregados. É um dos salões mais conhecidos localmente e conta hoje com cinco unidades espalhadas pela cidade. A fundadora do Salão A, que também trabalha como cabeleireira em suas unidades, foi entrevistada utilizando-se um roteiro de perguntas previamente elaboradas com auxílio da literatura sobre o tema utilizado. A entrevista ocorreu em janeiro de 2014, mesmo período no qual a proprietária teve seu trabalho observado, para fins da pesquisa, nas dependências de seu negócio.

- Salão B: é uma microempresa localizada em um bairro periférico da mesma cidade em que o salão A está situado. Além da proprietária e sua sócia, que dividem o espaço, não possui nenhum funcionário, 
porém ambas atendem seus próprios clientes e obtêm ganhos separados. A fundadora deste salão foi entrevistada e também teve seu trabalho observado, para fins da pesquisa.

As informações foram levantadas no período de dezembro de 2014 a janeiro de 2015. As entrevistas foram posteriormente transcritas e analisadas usando a técnica de análise de conteúdo, conforme explicada por Bardin (2009).

\subsection{Utilização recomendada}

Este caso de ensino pode ser usado como um instrumento de ensino-aprendizagem por estudantes de graduação, em disciplinas como Teoria das Organizações, Gestão Organizacional e Estratégia, que abordem temas como organizações, estrutura organizacional e estratégia.

\subsection{Plano de ensino}

Sugere-se que o caso seja trabalhado em dois momentos. Primeiro, antes da apresentação da literatura sobre as configurações da estrutura organizacional, conforme a concepção de Mintzberg (2015), momento em que os estudantes refletirão sobre a estrutura da organização de modo a realizar inferências sobre as características organizacionais representadas no início e no fim do caso. Ao apresentar uma perspectiva temporal da empresa, espera-se que os discentes possam identificar as principais características de cada configuração, bem como apontar dificuldades em suas transições, mesmo que de maneira intuitiva e superficial.

Como plano para a aplicação do caso, recomenda-se a divisão em grupos de quatro a cinco estudantes, com a proposta de incentivar a discussão sobre os pontos-chave do caso e novas perspectivas de tomada de decisão e estruturação da empresa.Considerando-se o tempo de aula de $1 \mathrm{~h}$ e $40 \mathrm{~min}$, dividir $15 \mathrm{~min}$ para a leitura e análise do caso, 30min para discussão das ideias de cada grupo, 35min para discussão geral entre os grupos e $20 \mathrm{~min}$ para fechamento.

A posteriori, com a explanação das ideias de Mintzberg (2015) sobre as cinco configurações, em especial a estrutura simples e burocracia profissional, espera-se que os discentes alcancem melhor compreensão do conteúdo, enquanto o relacionam com a históriaapresentada, em uma discussão que envolva toda a classe. É importante dar exemplos e usar recursos áudio visuais que caracterizam outras organizações como burocracia profissional, a exemplo de hospitais, universidades, confeitarias, entre outras.

Uma vez cientes da teoria, os estudantes deverão analisar novamente o caso perante uma perspectiva de maior embasamento teórico, concomitante ao aprofundamento de novas questões. Eles podem ser incentivados a pensar em outros tipos de organizações que podem apresentar as configurações estudadas, analisando que outros desdobramentos podem acontecer em sua estrutura e gestão.

Espera-se que os estudantes possam perceber e indicar pontos-chaves do processo de transformação da estrutura organizacional, criticando as decisões e reavaliando novos possíveis direcionamentos para a empresa estudada, assim como entender como esta se enquadra estruturalmente nas configurações propostas por Mintzberg (2015).

\subsection{Referencial teórico}

As empresas de pequeno porte formam uma importante parcela da economia brasileira, do seu mercado de trabalho e do mercado consumidor, oferecendo um extenso leque de produtos e serviços conforme apontado por Matos e Vasconcelos (2013). Os resultados dessas empresas e sua perenidade afetam e são afetados pelo contexto micro e macroeconômico e social. Nesse sentido, torna-se relevante compreender os aspectos do ambiente externo e sua influência na tomada de decisão dos gestores, bem como analisar o ambiente interno e como sua configuração pode afetar as decisões e os resultados obtidos. Nessa interação entre as empresas e seus ambientes interno e externo, as empresas necessitam estar em constante adaptação, dizem Borniger et al (2015), como princípio básico de sobrevivência. 
Para alcançar os objetivos propostos neste caso para ensino, faz-se necessário o conhecimento de alguns conceitos específicos sobre gestão e estrutura organizacional, sendo a última, afirmam Stoner e Freeman (2010), entendida como a maneira como atividades organizacionais são divididas, organizadas e coordenadas. A estrutura organizacional também pode ser definida como o desenho organizacional, o sistema,o qual possui uma forma hierárquica, com o encadeamento de funções, processos e sistemas de comunicação que refletem a situação atual de uma organização, como seu tamanho, sistema de produção, sua complexidade e dinâmica (MINTZBERG; LAMPEL;GOSHAL,2006).

A estrutura organizacional sustenta a estratégia, mas precisa ser repensada tendo em vista as demandas de mercado e de recursos da empresa, bem como o relacionamento com seus grupos de interesse (BORNIGER et al, 2015).

A estrutura organizacional é composta pela estrutura formal e informal. A primeira pode ser definida como o conjunto de regras e normas explícitas que definem a distribuição de tarefas, a hierarquia com seus níveis de autoridade e responsabilidade. O organograma é o instrumento clássico da estrutura formal utilizado para demonstrar a divisão hierárquica de uma organização. No entanto, o organograma, ou outro instrumento formal, não consegue refletir os relacionamentos informais que formam a estrutura informal. Esses relacionamentos afetam as decisões, o comprometimento e a eficiência nas organizações (STONER; FREEMAN, 2010).

Os tipos de estrutura organizacional mais citadassão: funcional; por produto ou mercado; por projeto e matricial. Assim, de acordo com o foco da gestão, a estrutura pode ser delimitada de acordo com a divisão das funções,sendo dividida em unidades de negócios (de acordo com o seu portfólio de produtos ou com os mercados nos quais atua), e pode contemplar estruturas mais flexíveis de acordo com os seus projetos em andamento, ou ser uma combinação de distribuição funcional com estrutura de projetos (STONER; FREEMAN, 2010).

Devido à complexidade organizacional e à necessidade de adequação aos mais diversos contextos de negócio, Mintzberg (2015) sugere que a estrutura organizacional não seja pensada de forma isolada e que sejam adotadas configurações, que são conjuntos que contemplam tipos de controle, graus de formalização e descentralização, sistemas de planejamento e estruturas que,ao serem pensados de forma conjunta, possibilitam a consistência interna organizacional.Para Ferreira, Gimenez e Grave (2003), essa forma de compreender a estrutura organizacional por meio de configurações, feita por Mintzberg (2015), é um instrumento importante para a compreensão da realidade organizacional por ser uma análise ampla, que contempla vários contextos, e também pelo método utilizado, que privilegia a descrição e a comparação entre as configurações, bem como o uso de tipologias para caracterizar cada estrutura organizacional.

Uma configuração é composta pelo arranjo de seis partes básicas da organização: essência operacional (quem desempenha o trabalho básico de produção/prestação de serviços), linha intermediária (média gerência que intermedeia a operação e a estratégia), ápice estratégico (gerencia todo o sistema), área de apoio (execução de serviços internos não diretamente ligados à atividade-fim da organização), tecnoestrutura (planejamento e controle do trabalho fora da hierarquia) e ideologia (abrange as tradições e crenças que distinguem uma organização das demais) (MINTZBERG et al., 2006), conforme demonstrado na figura 1: 
Figura 1 - As seis partes da organização

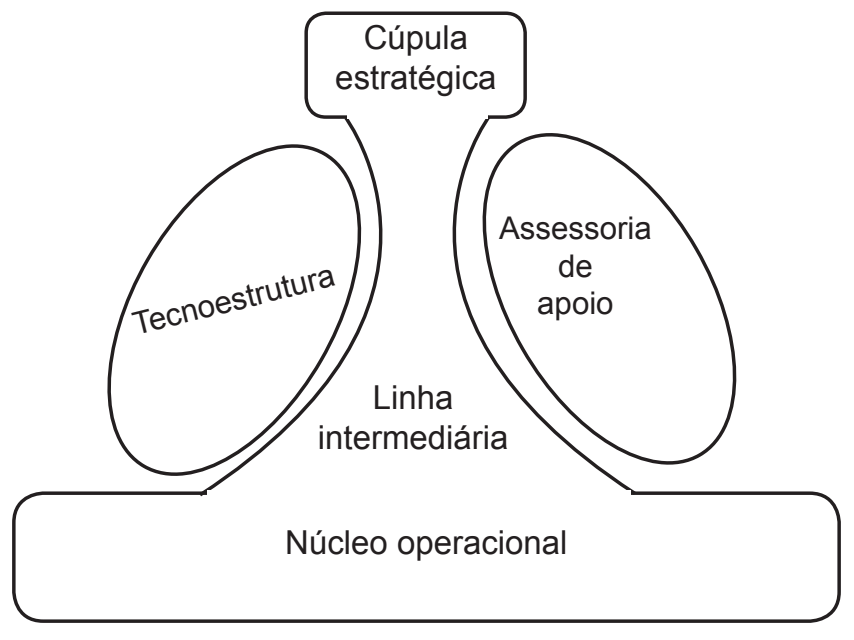

Fonte: Adaptado de Mintzberg (2015, p. 22).

Além das partes de uma organização, é preciso compreender os seus mecanismos de coordenação. O ajuste mútuo é a coordenação do trabalho por meio de processo de comunicação informal. A supervisão direta é feita por meio de um indivíduo que coordena, dando ordens e observando a execução feita por seus subordinados,os quais geralmente precisam executar seu trabalho juntos. A padronização dos processos de trabalho é feita pela programação do conteúdo do trabalho, de forma que, se algo acontecer fora da programação, será fácil identificar. A padronização de saída acontece não com a padronização dos processos, mas nos seus resultados. Já na padronização de habilidades são os funcionários que são padronizados por meio de seus conhecimentos e habilidades. A padronização de normas é feita com o compartilhamento de um conjunto de crenças comuns que norteiam e coordenam o que será feito (MINTZBERG, 2015; MINTZBERG et al., 2006).

Ademais, as partes da organização, seus mecanismos de controle e os fatores situacionais, como tamanho e idade, também influenciam nas configurações que se formam a partir daí e que podem ser, de acordo com a percepção de Mintzberg (2015): estrutura simples, burocracia mecanizada, burocracia profissional, estrutura divisional, adhocracia e missionária. O objetivo do presente estudo de caso é apresentar características de duas delas: estrutura simples e burocracia mecanizada, assim como apresentar os desafios e problemas que podem ocorrer quando da transição de uma para outra.

A estrutura simples é formada por um ou poucos gestores, e cada um deles geralmente lidera um grupo operacional que executa um trabalho básico. A organização tende a ser pouco formalizada, com uso mínimo de planejamento, treinamento e instrumentos de ligação. Se há pouca padronização, então a estrutura é orgânica e não depende de tecnoestrutura e da linha intermediária, porque a coordenação é feita diretamente pela cúpula estratégica utilizando a supervisão direta. É flexível, porém vulnerável. O principal gestor pode optar em mantê-la assim para evitar perder o controle (MINTZBERG et al., 2006). O quadro 3 apresenta a síntese das características da estrutura simples.

Quadro 3 - Estrutura simples

\begin{tabular}{|l|l|}
\hline Principal mecanismo de coordenação & Supervisão direta \\
\hline Parte chave da organização & Cúpula estratégica \\
\hline Principais parâmetros do design & Centralização; estrutura orgânica \\
\hline & Pequena e jovem \\
Fatores situacionais & Sistema técnico pouco elaborado \\
& $\begin{array}{l}\text { Ambiente simples e dinâmico } \\
\text { Cúpula da organização briga pelopoder } \\
\text { Não acompanha a moda }\end{array}$ \\
\hline
\end{tabular}

Fonte: Adaptado de Mintzberg (2015, p. 178) 
Já a burocracia profissional é uma configuração mais burocrática, pois depende mais de padronização das habilidades ou dos resultados do processo para sua coordenação. As organizações que precisam profissionalizar os seus serviços procuram por esse tipo de configuração, como é o caso de organizações prestadoras de serviços que dependem de profissionais altamente especializados, com controle sobre o seu trabalho, para desempenharem suas funções sem a necessidade de uma supervisão constante e direta. É o caso de uma universidade ou um hospital. A estrutura apresenta-se de forma mais horizontal, o poder de decisão flui pela hierarquia e não há muita necessidade de tecnoestrutura, mas comporta um grande número de pessoas na área de apoio para dar suporte aos profissionais altamente capacitados. É comum em ambientes complexos, porém com ambiente de competição estável. O quadro 4 demonstra algumas das características da burocracia profissional:

Quadro 4 - Burocracia profissional

\begin{tabular}{|l|l|}
\hline Principal mecanismo de coordenação & Padronização das habilidades \\
\hline Parte chave da organização & Núcleo operacional \\
\hline Principais parâmetros do design & $\begin{array}{l}\text { Treinamento, especialização horizontal das tarefas, } \\
\text { descentralização vertical e horizontal }\end{array}$ \\
\hline Fatores situacionais & $\begin{array}{l}\text { Ambiente estável e complexo; } \\
\text { Sistema técnico não regulado e não sofisticado; } \\
\text { Acompanha a moda }\end{array}$ \\
\hline
\end{tabular}

Fonte: Adaptado de Mintzberg (2015, p. 213).

O modelo de configurações de Mintzberg (2015) pode servir para analisar diferentes tipos de organização, como as organizações do terceiro setor, que foram objetos do estudo de Cunha et al (2011). Em seu estudo de caso, os autores identificaram uma estrutura organizacional complexa, onde observaram mais de uma força impulsionadora, mesmo que a entidade estudada possuísse estrutura e missão coesas. Com isso, eles afirmaram que a entidade possuía configuração híbrida, apresentando parâmetros de diferentes configurações, mas com o predomínio de duas: a burocracia mecanizada e a adhocracia. Os autores concluem que a presença de elementos de ambas as estruturas reflete características do próprio setor no qual a entidade está inserida, onde se faz uso de instrumentos de gestão mais sistemáticos e padronizados como forma de atingir a profissionalização. Este estudo é interessante, pois corrobora o que o próprio Mintzberg (2015) afirma sobre a possibilidade de, quanto mais complexa for a organização,haver mais características de várias configurações.

Outro trabalho que demonstra o uso das configurações de Mintzberg (2015) na análise da estrutura organizacional é o de Madeira e Pereira (2011), que fazem uma correlação entre o conceito de burocracia de Max Weber com os conceitos de burocracia mecanizada e burocracia profissional, tendo como foco as estruturas presentes nas terceirizações e parcerias, com o objetivo de identificar o principal mecanismo de coordenação. Os autores relacionaram a burocracia mecanizada com a terceirização entendendo, no entanto, que não se pode afirmar que essa última seja uma burocracia mecanizada "pura", mas uma configuração híbrida, com diferentes configurações em diferentes partes das organizações. A tecnoestrutura é peça-chave da organização por ter a responsabilidade pela sistematização e a padronização dos resultados que se espera da empresa contratada, em uma clara transferência de responsabilidade pela execução do trabalho. Já no caso das parcerias, os autores apontam a burocracia profissional como sua configuração básica, em que o núcleo operacional é a peça-chave da organização,com o seu repertório de padrões, conhecimento e habilidades que são aplicados para encontrar cada solução adequada às diferentes situações diagnosticadas. Por fim, os autores concluem que os conceitos de burocracia de Weber continuam válidos e atuais e que a sua junção com as configurações de Mintzberg (2015) amplia as possibilidades de construir organizações mais eficientes e eficazes.

De acordo com Ferreira, Gimenez e Grave (2003), o modelo de configurações de Henry Mintzberg é um importante instrumento para a compreensão da realidade organizacional devido a sua amplitude e seu método comparativo de análise. No entanto, os autores alertam que é preciso ter cuidado, pois 
as configurações são aproximações, são modelos genéricos que representam múltiplas realidades, e nenhuma delas especificamente visa auxiliar na análise e apontar tendências.

Outra maneira de estudar a estrutura organizacional é relacioná-la com a estratégia adotada pela empresa, como a pesquisa desenvolvida por Borniger et al (2015), que combinam três visões distintas de estratégia:orientada pelo ambiente externo, orientada pelo ambiente interno, e relacional. Com a visão orientada pelo ambiente externo, a análise da estrutura organizacional se dá pelo grau de centralização das informações e decisões nos níveis mais altos. Já com visão estratégica focada no ambiente interno, a análise da estrutura organizacional é feita com relação à autonomia para ação, poucos níveis hierárquicos e troca de conhecimento tácito de forma lateral. E, por fim, a visão relacional busca analisar a flexibilidade quanto aos papéis, aos fluxos de informação dependentes de cada situação, à interdependência, à decisão tomada em conjunto e como a estrutura transcende as fronteiras organizacionais.

\subsection{Questões para discussão}

As questões abaixo podem auxiliar na identificação e análise dos principais pontos relacionados às mudanças na estrutura organizacional e suas possíveis configurações. Há um fio condutor que perpassa as questões e que é apresentado no item seguinte, onde é feita a conexão com a literatura, apontando assim, caminhos possíveis para a resolução dos problemas enfrentados pela empresa apresentada.

\section{Questões:}

1) Considerando as configurações de Henry Mintzberg, como pode ser caracterizada a empresa da Mariquinha, nos seus sete primeiros anos? Quais os principais elementos que justificam esta caracterização?

2) Nesta primeira fase, como se apresenta a questão de poder, da hierarquia e os critérios de contratação?

3)Ainda considerando a primeira fase, que tratamento é dado para a questão do conhecimento na empresa?

4) Identifique e caracterize, ao longo do texto, evidências de cada uma das seis partes da configuração de Mintzberg (2015) no caso estudado.

5) De acordo com os estudos de Mintzberg (2015),porque a contratação de um gestor administrativo para liderar a equipe de profissionais do salão de beleza não alcançou os objetivos esperados por Mariquinha?

6) Cite quais os principais problemas a serem enfrentados por Mariquinha para transformar sua empresa da estrutura inicial para uma nova estrutura que seja adequada e que comporte seu crescimento estrutural e econômico?

7) Diante dos fatos e do crescimento da empresa da Mariquinha, para qual configuração, segundo os conceitos de Mintzberg (2015) sobre configurações da estrutura organizacional, a empresa deveria ser direcionada? Por quê?

8) Com relação aos controles adotados, houve evolução? Essa evolução foi constante e aprimorada? Quais seriam os controles e indicadores necessários para que a Mariquinha desenvolvesse mecanismos de coordenação?

\subsection{Análise do caso e possíveis respostas às questões}

\section{Questão 01}

Nos sete primeiros anos da existência da empresa Sempre Bela Cabelereiros, ela apresentava uma estrutura denominada de: estrutura simples. Os elementos que sustentam essa afirmativa levam em conta que a empresa estava em sua fase inicial de operações e era de pequeno porte. No que diz respeito ao número de funcionários, não havia muitos na execução das tarefas. Quanto ao faturamento da empresa, apesar ter se tornado maior com o passar dos anos, apresentava valores pouco expressivos. Por fim, em se 
tratando da sua estrutura de cargos, a empresa apresentava poucos cargos, mas foram sendo ampliados conforme o crescimento orgânico da empresa, e também se pode observar que as divisões de tarefas eram muito mais reflexo das competências de execuçãodo que demandadas pela estrutura organizacional.

Outro elemento importante e que evidencia tal aspecto é que, na cúpula estratégica, a própria Mariquinha estava posicionada como parte-chave da organização. Desse modo, caracterizava-se ainda por ter um design altamente centralizador, fato que se reflete no momento em que a fundadora considerou que ela e somente ela,enquanto dona do negócio, seria responsável pela execução de quase todas as atividades e pelos resultados do empreendimento.

\section{Questão 2}

Quanto ao poder, percebe-se que esse aspecto sempre foi muito bem estabelecido desde o início da empresa, pois a Mariquinha jamais abriu mão dele; pelo contrário, sempre que possível enfatizava que era detentora do poder. Tal situação é ratificada e trazida para o concreto pelo uso dos elementos da hierarquia. Mesmo não havendo um organograma formal, a Mariquinha não media esforços para que as mais diversas representações demonstrassem quem era a chefe e quem éramos subordinados, mesmo diante do aumento de demanda por conta do mercado aquecido, em que havia ainda uma tendência de expansão em relação à variabilidade dos serviços prestados. O ambiente apresentava uma situação favorável ao crescimento e à expansão da empresa, mas o perfil centralizador da empresária limitou e atrasou o seu crescimento.No que diz respeito ao processo de contratação, ele estava completamente contaminado por elementos subjetivos, haja vista que se tinha como critério de contratação ser uma pessoa conhecida, do seu círculo de relações, em quem ela pudesse confiar. Isso demonstra uma forma ainda amadora de ver o próprio negócio, com elementos da estrutura informal (relações interpessoais) sendo mais preponderantes do que a descrição de cargos e normas estabelecidas.

\section{Questão 3}

Mesmo vivenciando algumas situações complicadas de sobrecarga de atividades, Mariquinha julgou não ser necessário contratar um profissional, por exemplo, para auxiliá-la nos serviços de corte e penteado, e insistiu em contratar uma auxiliar de limpeza. Para ela, ninguém podia executar o trabalho tão bem quanto ela mesma, o que evidencia que somente o conhecimento advindo da experiência era importante e levado em conta.

Mesmo que os profissionais tenham comprovado possuírem conhecimento formal com apresentação de certificados e diplomas, o peso da experiência e conhecimento adquirido pela Mariquinha era maior. Essa situação está relacionada ao exemplo citado por Mintzberg (2015) no início do livro, quando apresenta a história da artesã e sua forma de trabalhar dentro da estrutura simples. Nessa realidade, o capital intelectual não é apropriado e estruturado pela organização para que os demais profissionais possam se desenvolver e ter mais autonomia, ampliando as possibilidades de ganhos, como socialização das tarefas, complementariedade no desempenho de tarefas (um fazendo uma parte e o outro sendo capaz de dar sequência, pois é conhecedor do que se espera) e a criação de profissionais multitarefas.

\section{Questão 4}

As seis partes da configuração organizacional e suas características são:

- Núcleo operacional ou essência operacional (são os profissionais que desempenham o trabalho básico de produção/prestação de serviços);

- Nível intermediário ou linha intermediária (onde está a média gerência, cuja atividade, além de planejar, liderar, organizar e controlar,também envolve intermediar as questões de operacionalização das estratégias);

- Cúpula estratégica ou ápice estratégico (conforme o porte e a configuração jurídica da organização, pode-se dizer que ali se encontra o conselho de acionistas, os donos e os diretores, sendo esse 
grupo de profissionais que emanam as estratégias da organização, além da gerência de todo o sistema);

- Assessora de apoio ou área de apoio (suas ações envolvem a execução de serviços internos, que não são menos expressivos, mas que podem ser desempenhados por profissionais terceirizados, pois não estão ligadas à atividade fim da empresa,);

- Tecnoestrutura (abrange atividades de planejamento e controle do trabalho fora da hierarquia);

- Ideologia (ela abrange aspectos muito mais subjetivos, como as tradições e crenças, que distinguem uma organização das demais).

Sabendo-se que a empresa da Mariquinha está em processo de transição entre a estrutura simples e a estruturado tipo burocracia profissional, a resposta deve levar em consideração a estrutura que irá ser consolidada, que é a burocracia profissional. Assim, cabe observar que a empresa não apresentará todos os elementos, sejam cargos,sejam profissionais ocupando os cargos que compõem sua nova estrutura. Pode-se, entretanto, caracterizar a transformação como:

- Cúpula estratégica: Atualmente, Mariquinha é uma empresária bem-sucedida, conta com seis unidades de salões de beleza espalhados pela cidade, trabalha e administra o seu empreendimento há mais de duas décadas.

- Nível intermediário: Mariquinha decidiu contratar um profissional para fazer a gestão da unidade e pela primeira vez contratou alguém fora do salão, com experiência em administração de loja em shopping center.

- Tecnoestrutura: Com a nova estrutura, atividades e controles, aumentou a pressão sobre a agenda da fundadora que, além de continuar com as atividades de cabeleireira, também controlava as atividades administrativas e financeiras junto com sua gerente, mas utilizando o livro caixa e outras "folhinhas de anotações".

- Assessoria de apoio: Pessoas ligadas ao atendimento e agendamento.

- Núcleo operacional: as cabelereiras e demais profissionais envolvidos na operação

- Ideologia: Quanto à ideologia, ela está em processo de transição e, portanto, envolve um ir e vir nos elementos que a caracteriza, isto é, em um momento, a empresa apresenta elementos de uma estrutura de burocracia profissional e, em outros, de uma estrutura simples. Esse é um dos aspectos que mais penalizam as organizações em um momento de transição e implica em perdas momentâneas de identidade e necessidade de segurança, o que determina o retorno aos elementos da cultura da estrutura que se está tentando deixar.

\section{Questão 5}

A contratação de um profissional para ocupar um cargo de gestão em uma estrutura simples em fase de transição para uma burocracia profissional é um momento muito especial e potencialmente problemático, uma vez que o profissional irá "ocupar" um espaço que era da dona do negócio. Esse processo deve ser totalmente capitaneado pelo dono da empresa, sob a pena de haver mais desgastes do que acertos. Tornou-se evidente que um administrador que não possuísse nenhum conhecimento técnico demandado por um salão de beleza, não poderia, na visão da equipe, dizer o que era melhor para os empregados com anos de carreira.

O núcleo operacional é a peça-chave da organização,e Mintzberg et al. (2006) afirmam que a burocracia profissional está baseada na coordenação da padronização das habilidades e em seus parâmetros de design associados, o treinamento e a doutrinação. Contratar profissionais especializados, devidamente treinados e doutrinados, para o núcleo operacional e depois lhes conceder considerável controle sobre seu próprio trabalho. 


\section{Questão 6}

Os problemas são de diversas ordens, e todos potencializados por conta da falta de experiência da empreendedora no que diz respeito à gestão de sua estrutura organizacional ao longo do tempo. Assim, quando a empresa evoluiu de uma estrutura simples para a burocracia profissional, Mariquinha enfrentou, primeiramente, o problema de centralizar todas as atividades, sendo preciso quebrar o conceito da fase inicial do salão de beleza, de que tudo dependia da sua ação e decisão. Ela também teve problemas em aceitar a descentralização causada pela nova estrutura que estava se formando, e suas atitudes ocasionaram a maior parte dos problemas. Percebe-se que as consequências muitas vezes não são tão perceptíveis a ponto de facilmente se fazer uma correção entre mudança de estrutura e medo de delegar poderes, o que determina um lapso de tempo para que haja a transição dessa fase.

Ao tentar manter a centralização,aspecto natural da estrutura simples, Mariquinha impediu o crescimento da empresa. O fato de não compreender e não aceitar que sua estrutura estava em um processo de transformação,o qual demandaria uma série de mudanças, dentre elas a autonomia requerida pela nova estrutura (burocracia profissional),gerou um catalizador (elemento que retarda ou acelera uma reação), que agiu sobre um grande número de problemas, alguns de fácil solução e de pouco impacto, e outros muito mais complexos e cuja a solução afetaria a expansão do empreendimento.

\section{Questão 7}

Considerando as características da atividade da empresa, o fato de sua estrutura atual ser uma estrutura simples e o crescimento dela ao longo dos anos, a estrutura que melhor suportaria o negócio seria a burocracia profissional. No que diz respeito à estrutura organizacional, é a mais adequada para ser adotada sempre que a organização se encontra em um ambiente estável, porém complexo, que demanda controles, descentralização, treinamento, autonomia, dentre outros.

O processo de transição não é efetuado de forma simples, pois requer o envolvimento da Mariquinha no sentido de entender o que vem a ser sua estrutura atual e a estrutura para a qual a empresa deve migrar, sob pena de não haver uma real mudança de atitude. Nesse processo de "convencimento", devese levar em conta o nível de informação da Mariquinha, sua disposição para mudar, a melhor abordagem a ser adotada para que haja a compreensão dos elementos envolvidos na transição, tais como: levantamento das necessidades de treinamento de toda a equipe, concepção de autonomia, desenho de processos de gestão, identificação e seleção dos processos a serem controlados e das formas de controle e seus respectivos indicadores.

Deve-se lembrar que no processo de transição não cabe a criação de cargos e a consequente contratação de profissionais apenas para indicar que a empresa está migrando para uma nova estrutura. O que deve ocorrer é o desenho das atividades a serem desempenhadas, mesmo que sejam ocupadas pelos profissionais que já se encontram na empresa, para posteriormente haver uma reestruturação e a contratação de ocupantes dos cargos na tecnoestrutura, no nível intermediário e para assessoria de apoio. Enfim, o processo deve respeitar a estrutura atual e ser realizado de forma orgânica, isto é, conforme a empresa suporta e consolida as mudanças.

\section{Questão 8}

Não houve evolução nos controles adotados, pois eles eram e permaneceram simples, o que fragiliza muito a construção da nova estrutura organizacional, podendo criar uma série de problemas, principalmente relativos ao estoque e ao financeiro. Caberá a Mariquinha, aprimorar os controles para obter mais confiança e aceitação do "preço" que se tem que pagar com o crescimento da empresa.

Os controles vãodesde o estoque até o financeiro e o relacionamento com os clientes. Para tanto, poderia ser adquirido um software de gestão que permitisse a Mariquinha acompanhar a movimentação financeira, do estoque de produtos, de atendimento e dos dados dos clientes, cujo resultado levaria a um aprimoramento nos mecanismos de coordenação da empresa e, por sua vez, estes acompanhariam o desenvolvimento da empresa,permitindo que suplantasse a fase de transição de uma estrutura para a 
outra. Entretanto, esse processo de consolidação demandaria muitas outras mudanças, tanto no perfil da proprietária como nos processos adotados pela empresa, que deveriam ser revistos e reestruturados.

\section{Referências}

BARDIN, L. Análise de Conteúdo. Lisboa: Edições 70, 2009.

BORNIGER, C. et. al. Relacionamento entre estratégia e estrutura organizacional: um estudo contemporâneo de casos múltiplos. Revista Ciências Administrativas, Fortaleza, v. 21, n. 1, p. 11-41, jan./jun. 2015.

CUNHA, L. T.et. al. Configuração da estrutura organizacional no terceiro setor: o caso EDISCA. REGEUSP - Revista de Gestão da USP, São Paulo, v. 18, n. 3, jul/set, p. 385-407, jul./set. 2011.

FARIAS FILHO, M. C.; ARRUDA FILHO, E. J. M. Planejamento da pesquisa científica. São Paulo: Atlas, 2013.

FERREIRA, F. V.; GIMENEZ, F. A. P.; GRAVE, P. S. Modelo de configurações: verificações empíricas da Teoria de Estrutura Organizacional de Mintzberg.Revista Alcance, Biguaçu (SC), v. 10, n. 2, p. 258-283, Maio-Ago. 2003.

MADEIRA, G. S.; PEREIRA, M. Desenhando estruturas organizacionais: das burocracias de Weber e Mintzberg às organizações contemporâneas. In:CONVIBRA ADMINISTRAÇÃO - CONGRESSO VIRTUAL BRASILEIRO DE ADMINISTRAÇÃO, 8.,2011, São Paulo. Anais...São Paulo: CONVIBRA, 2011. p. 1-14. Disponível em: <http://docplayer.com.br/12491540-Desenhando-estruturasorganizacionais-das-burocracias-de-weber-e-mintzberg-as-organizacoes-contemporaneas.html>. Acesso: 21 ago. 2017

MATOS, P.; VASCONCELOS, A. Análise de causalidade da mortalidade das pequenas empresas no Brasil. Revista Ciências Administrativas, Fortaleza, v. 19, n. 1, p. 13-34, jan./jun. 2013.

MINTZBERG, H. Criando organizações eficazes: estruturas em cinco configurações. 2 ed. São Paulo: Atlas, 2015.

MINTZBERG, H.; LAMPEL, J.; GHOSHAL, S. Processo de Estratégia. Porto Alegre: Bookman, 2006. STONER, J. A. F.; FREEMAN, R. E. Administração. 5a ed. rev. Rio de Janeiro: LTC, 2010.

Submetido em: $24 / 11 / 2016$

Aprovado em: 07/06/2017 